\title{
PENELUSURAN INFORMASI DI PERPUSTAKAAN UNAIR SELAMA PANDEMI COVID-19
}

\author{
Turwulandari \\ Perpustakaan Universitas Airlangga \\ turwulandari@staf.unair.ac.id
}

\begin{abstract}
ABSTRAK
Pandemi COVID-19 yang mewabah di seluruh dunia mempengaruhi berbagai aspek dalam kehidupan masyarakat. Perpustakaan perguruan tinggi dan civitas akademik di dalam perguruan tinggi juga tak luput dari dampak pandemi ini.Untuk tetap memberikan layanan kepada pengguna maka perpustakaan menyediakan layanan penelusuran informasi bagi civa unair secara online.Penelusuran informasi juga diartikan sebagai usaha untuk menemukan suatu informasi baik dari sumber berupa buku, artikel, internet dan lainnya dengan mendapatkan hasil yang berupa teks, naskah, rekaman, maupun video yang sesuai dengan minat dan keinginan pemakai.
\end{abstract}

Kata kunci : penelusuran, informasi, onlinea

\section{PENDAHULUAN}

Perpustakaan Perguruan tinggi adalah tempat untuk mencari informasi bagi civitas akadenik di suatu perguruan tinggi. Sebagaimana fungsi perpustakaan, sumber informasi yang ada di perpustakaan dapat dimanfaatkan oleh pemustaka untuk menunjang kegiatan pendidikan. Tersedianya koleksi perpustakaan yang sesuai dengan kebutuhan pemustaka dapat meningkatkan kualitas layanan perpustakaan (Ingvaldsen, 2017). Inilah salah satu alasan yang menjadikan pemustaka tetap memilih untuk mendapatkan informasi dari perpustakaan. Terlepas dari fakta bahwa saat ini banyak kemudahan yang bisa didapatkan dari internet dengan kecanggihan teknologi informasi, salah satunya dalam mengakses informasi. Selain itu, sumber informasi di perpustakaan dapat dipertanggungjawabkan sumbernya, yang tentunya berbeda dengan informasi di internet yang harus dievaluasi terlebih dahulu.

Tentunya, banyak sumber informasi yang bisa didapatkan di perpustakaan apabila pemustaka berkunjung ke perpustakaan. Tetapi hal ini tidak bisa dilakukan oleh perpustakaan ketika ada pandemi COVID-19. Semua menjadi berubah dan pustakawan diharuskan work from home. Nah, apa yang dapat dilakukan di tengah pandemi ini menjadi tantangan bagi pustakawan agar layanan perpustakaan dapat tetap berjalan dan dapat dimanfaatkan oleh pemustaka.

Mencoba menjawab tantangan saat pandemi seperti ini dalam kaitannya menyediakan sarana penelusuran informasi perpustakaan yang dapat digunakan oleh civitas akademik, Perpustakaan UNAIR menyediakan layanan yang berbasis internet. Salah satu layanan yang diberikan oleh Perpustakaan Universitas Airlangga (UNAIR) selama wabah Covid-19 adalah layanan penelusuran informasi. Layanan ini memungkinkan mahasiswa untuk mendapatkan 
informasi berupa artikel jurnal maupun e-books sesuai dengan kebutuhan pemustaka. Adanya layanan penelusuran ini diharapkan akan dapat membantu pemustaka dalam melakukan penelusuran informasi yang dibutuhkan. Dalam menggunakan layanan ini, mahasiswa harus mengisi google form yang telah di sediakan oleh perpustakaan.

Berdasarkan uraian diatas, tujuan dari penelitian ini adalah untuk mendeskripsikan sarana layanan penelusuran informasi Perpustakaan Universitas Airlangga selama pandemi Covid-19.

\section{TINJAUAN PUSTAKA}

\section{Perpustakaan}

Penggunaan teknologi komputer sekarang ini sudah sangat umum. Tidak ketinggalan perpustakaan pun memanfaatkan teknologi tersebut untuk melakukan layanan, terutama layanan penelusuran. Dengan adanya teknologi informasi dapat memungkinkan layanan menjadi cepat dan temu kembali informasi menjadi lebih mudah.

Menurut (Yusuf \& Subekti, 2010) perpustakaan disebut sebagai sumber informasi karena memenuhi ciri-ciri sebagai berikut:

1. Tempat dihimpunnya segala jenis informasi baik cetak maupun digital

2. Tempat diolahnya berbagai macam sumber informasi

3. Tempat disebarkannya segala macam informasi ke pengguna yang membutuhkannya

4. Sebagai tempat lahirnya informasi dalm hal tertentu

5. Tempat dipeliharanya informasi yang terekam

Sumber informasi yang ada di perpustakaan sangat beragam, mulai dari koleksi tercetak hingga digital. Sumber informasi juga dimanfaatkan sesuai dengan kesesuaian fungsi dari sumber informasi tersebut. Martoatmojo (1993) mengatakan ada dua macam sumber informasi yaitu sumber informasi primer dan sumber informasi sekunder. Sumber informasi primer adalah sumber informasi yang memaparkan adanya informasi tersebut. Sumber informasi primer diantaranya adalah makalah pertemuan, tesis, disertasi, artikel ilmiah, skripsi, majalah, dan sebagainya. Sedangkan sumber informasi sekunder adalah daftar atau pencatatan dari sumber informasi primer. Sumber informasi sekunder ini diantaranya adalag bibliografi, catalog indeks dsb.

\section{Penelusuran Informasi}

Penelusuran informasi adalah jasa perpustakaan yang disajikan pada pengguna yang pada umumnya melalui surat untuk mendapatkan informasi mengenai subjek tertentu. Dalam pengertian lain, penelusuran informasi adalah memberi bantuan kepada pengguna dalam menelusur informasi dengan menggunakan bahan pustaka yang ada di perpustakaan ataupun alat alat penelusuran yang lain.

Penelusuran informasi sangat berkaitan erat dengan konsep literasi informasi. Literasi informasi merupakan kemampuan untuk menentukan, mencari, menemukan, menganalisis, dan mengevaluasi informasi. Menurut American Library Association dalam anne landoy ( 24 ) 2020 menjelaskan bahwa literasi informasi adalah kemampuan individu untuk mengetahui kapan informasi dibutuhkan kemampuan untuk mencari, mengevaluasi, dan menggunakan secara efektif informasi yang dibutuhkannya. Literasi informasi mempunyai 3 (tiga) kemampuan penting, yaitu 1) Mengakses informasi--pengguna harus bisa mengakses informasi 
dengan cara yang efisien dan tepat guna. 2) Mengevaluasi informasi--pengguna harus dapat mengevaluasi informasi secara kritis dan kompeten. 3) Menggunakan informasi--pengguna harus dapat menggunakan informasi dengan cara yang tepat benar, dan kreatif.

Pada pertemuan ketiga IFLA di Mexico pada tahun 2002, terdapat 8 (delapan) standar literasi informasi untuk pendidikan tinggi, yaitu:

1. Memahami struktur pengetahuan dan informasi,

2. Menentukan jenis informasi yang dibutuhkan,

3. Membangun strategi untuk mencari dan menemukan kembali informasi,

4. Mendapatkan informasi,

5. Menganalisis dan mengevaluasi informasi,

6. Mengintegrasi, membuat, dan menggunakan informasi,

7. Menampilkan informasi yang telah ditemukan, dan

8. Memperhatikan hak cipta.

Dari kedelapan kemampuan spesifik literasi informasi untuk pendidikan tinggi tersebut, sumber informasi sangat penting untuk diperhatikan karena berkaitan dengan hak cipta dan kebenaran informasi yang ditemukan oleh pemustaka. Perpustakaan sebagai pengelola informasi mempunyai peran yang sangat strategis terutama berkaitan dengan penyediaan layanan penelusuran informasi yanv sapat dipercaya.

\section{METODE PENELITIAN}

Penelitian ini menggunakan metode yaitu dengan mendeskripsikan data yang berkaitan dengan layanan penelusuran di Perpustakaan UNAIR. Data diperoleh dari observasi yaitu mengamati layanan penelusuran yang ada di Perpustakaan UNAIR. Studi pustaka yaitu mempelajari bahan pustaka yang berhubungan dengan topik yang dibahas.

\section{PEMBAHASAN}

\section{Sumber Layanan Penelusuran Informasi Perpustakaan UNAIR}

Saat ini penggunaan teknologi informasi sudah sangat umum untuk mewujudkan layanan penelusuran informasi. Pandemi juga menjadikan berbagai lembaga menyediakan berbagai sarana yang berbasis pada teknologi informasi, salah satunya perpustakaan. Perpustakaan UNAIR memberikan terobosan layanan baru yang berbasis teknologi informasi untuk membantu civitas akademik dapat dengan mudah mendapatkan informasi dari sumber informasi yang ada di perpustakaan. Layanan tersebut yaitu layanan sarana penemuan kembali informasi. Layanan ini memanfaatkan pangkalan data milik perpustakaan UNAIR. Pangkalan data dapat didefinisikan sebagai himpunan dokumen atau berkas yang berkaitan antara satu dengan lainnya berkumpul menjadi satu dan dapat digiunakan sebagi satu kesatuan dan dapat diakses secara online. Pangkalan data ini berisi berbagai sumber informasi seperti ebook, e-journal, dan lain sebagainya (Nelisa \& Ardoni, 2018; Purwono, 2008; Reynaldi \& Rahmah, 2014).

Lebih lanjut, berikut merupakan sarana penelusuran yang ada di Perpustakaan Unair yang dapat memenuhi kebutuhan informasi pengguna diantaranya:

1. Menggunakan e-resources yang ada di Perpustakaan UNAIR 


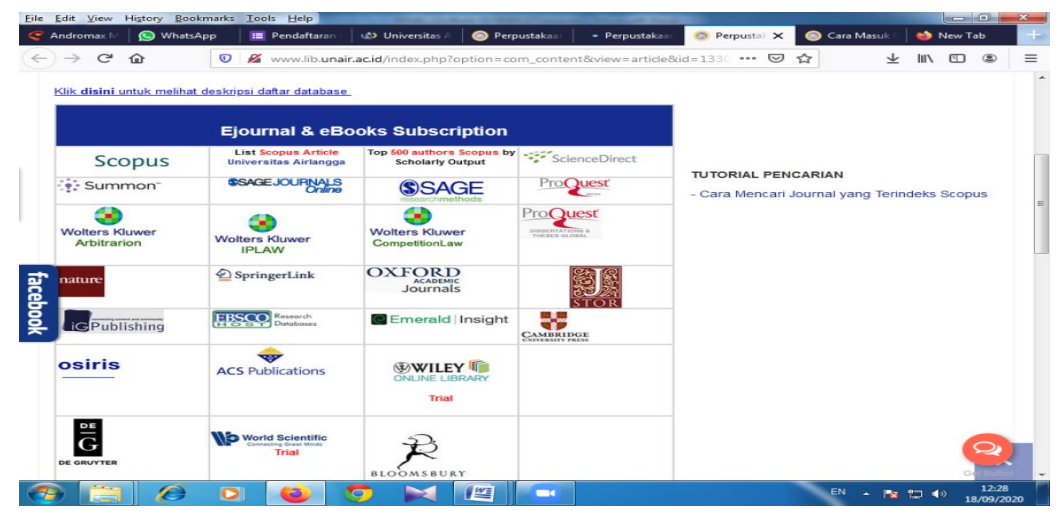

Gambar 1. Tampilan e-resources yang dilanggan

E-resources merupakan kumpulan berbagai sumber informasi online atau digital milik perpustakaan UNAIR. E-resources terdiri dari e-journal dan e-book. E-journal dan e-books ini sudah dilanggan oleh perpustakaan UNAIR, sehingga pengguna dapat mengakses koleksi ejournal dan e-books secara gratis. Beberapa e-journal dan e-books yang telah dilanggan oleh perpustakaan UNAIR adalah SCOPUS, SAGE, ProQuest, OXFORD, Wiley, dan sebagainya.

\section{Menggunakan OPAC}

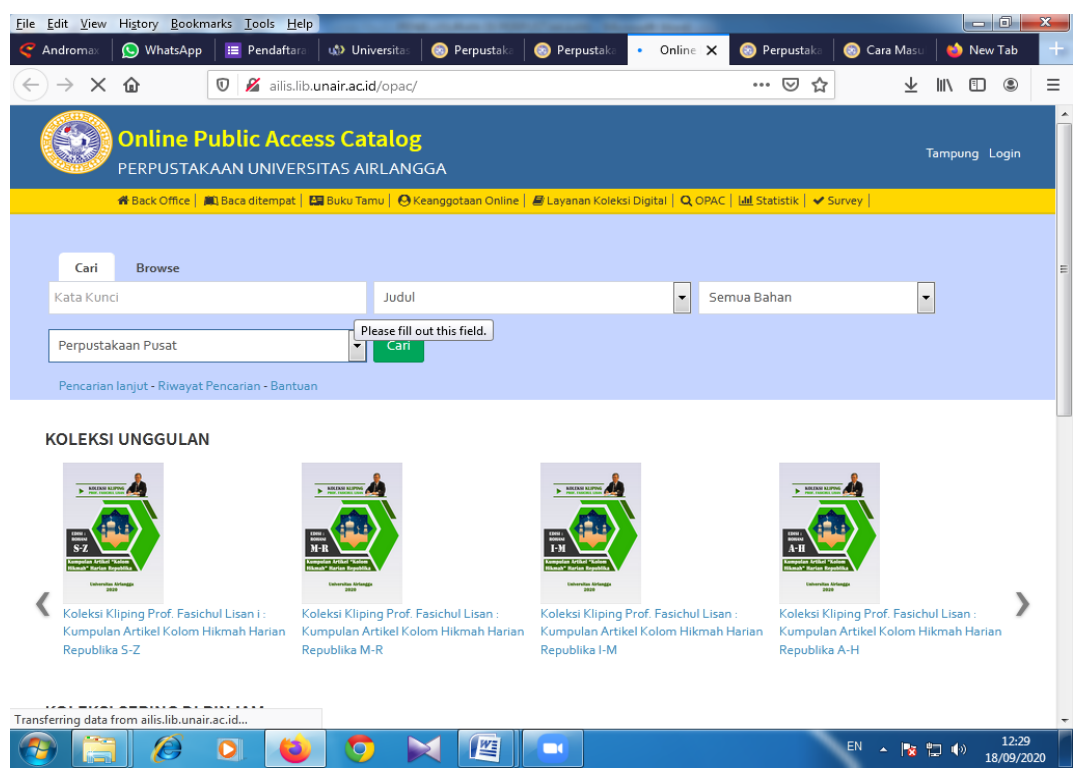

Gambar 2. Tampilan halaman awal OPAC

Gambar diatas menunjukkan tampilan halaman awal OPAC Perpustakaan UNAIR. Pada OPAC, pengguna dapat mencari dan mengakses koleksi Perpustakaan UNAIR. Pengguna dapat melakukan penelusuran informasi pada kolom pencarian yang telah disediakan dengan mengunakan kata kunci seperti subyek, judul, dan sebagainya. Pengguna juga dapat mencari koleksi yang disediakan baik di perpustakaan pusat maupun ruang baca tiap-tiap fakultas. Pada halaman awal OPAC, ditampilkan juga koleksi unggulan yang bisa dibaca oleh pengguna. Selain itu, pada OPAC juga disediakan menu layanan koleksi digital apabila pengguna ingin mencari sumber informasi lain berupa koleksi digital. 


\section{Menggunakan e-books}

Sarana penelusuran informasi lain yang disediakan oleh Perpustakaan UNAIR adalah berupa e-books. Koleksi digital berupa buku atau e-books dapat dibaca langsung oleh pengguna perpustakaan dengan mengakses berbagai fitur yang telah disediakan. Seperti yang telah dijelaskan diatas, koleksi e-book bisa dicari dari sumber informasi yang telah dilanggan perpustakaan dan koleksi digital perpustakaan.

4. Menggunakan aplikasi gratis

Banyak aplikasi dan website dari internet baik itu untuk mengunduh buku maupun artikel yang bisa digunakan secara gratis. Misalnya saja, pdf.drive.com yang menyediakan buku-buku dan artikel baik itu bahasa indonesia maupun buku buku luar negeri dan dapat diunduh.Selain itu bisa juga memanfaatkan ; e-resources perpustakaan Nasional;dan ; http://garuda.ristekbrin.go.id . Sehingga pengguna dapat memenuhi kebutuhan informasinya dengan lebih mudah dan mendapatkan informasi dari sumber yang bisa dipertanggungjawabkan (Purwono, 2008).

\section{Evaluasi Layanan Penelusuran Informasi Perpustakaan UNAIR}

Dalam menyediakan layanan, tentunya tidak luput dari adanya kendala yang dihadapi saat layanan disediakan dan digunakan oleh pengguna. Kendala-kendala yang ditemukan tersebut kemudian bisa menjadi bahan evaluasi dan pertimbangan untuk meningkatkan layanan penelusuran informasi di masa yang akan datang. Berdasarkan data yang telah dikumpulkan, berikut adalah data pemustaka yang memanfaatkan layanan penelusuran selama pandemi covid 19 antara bulan april sampai dengan juli 2020 di perpustakaan unair:

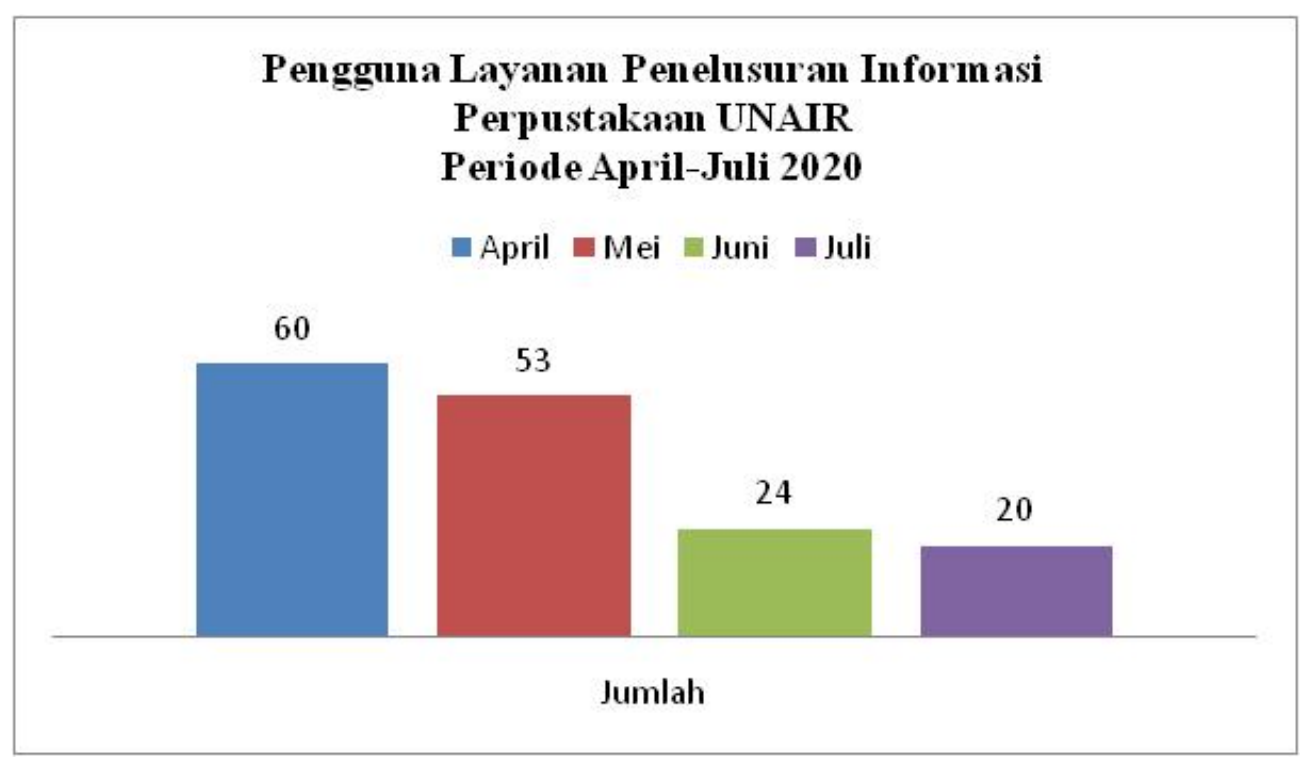

Gambar 3. Grafik Pengguna Layanan Penelusuran Informasi April-Juli 2020 Sumber: diolah dari data primer

Pada grafik diatas, penggunaan layanan penelusuran informasi Perpustakaan UNAIR pada bulan April menunjukkan angka pengguna paling banyak yaitu 60 pengguna, disusul pada bulan Mei sebanyak 53 pengguna. Selain itu, dapat dilihat adanya penurunan penggunaan layanan penelusuran informasi dari bulan ke bulan. Hal ini bisa disebabkan karena pada bulan 
Juni-Juli ada libur panjang dan persiapan ujian akhir semester. Sehingga, penggunaan layanan penelusuran informasi menurun.

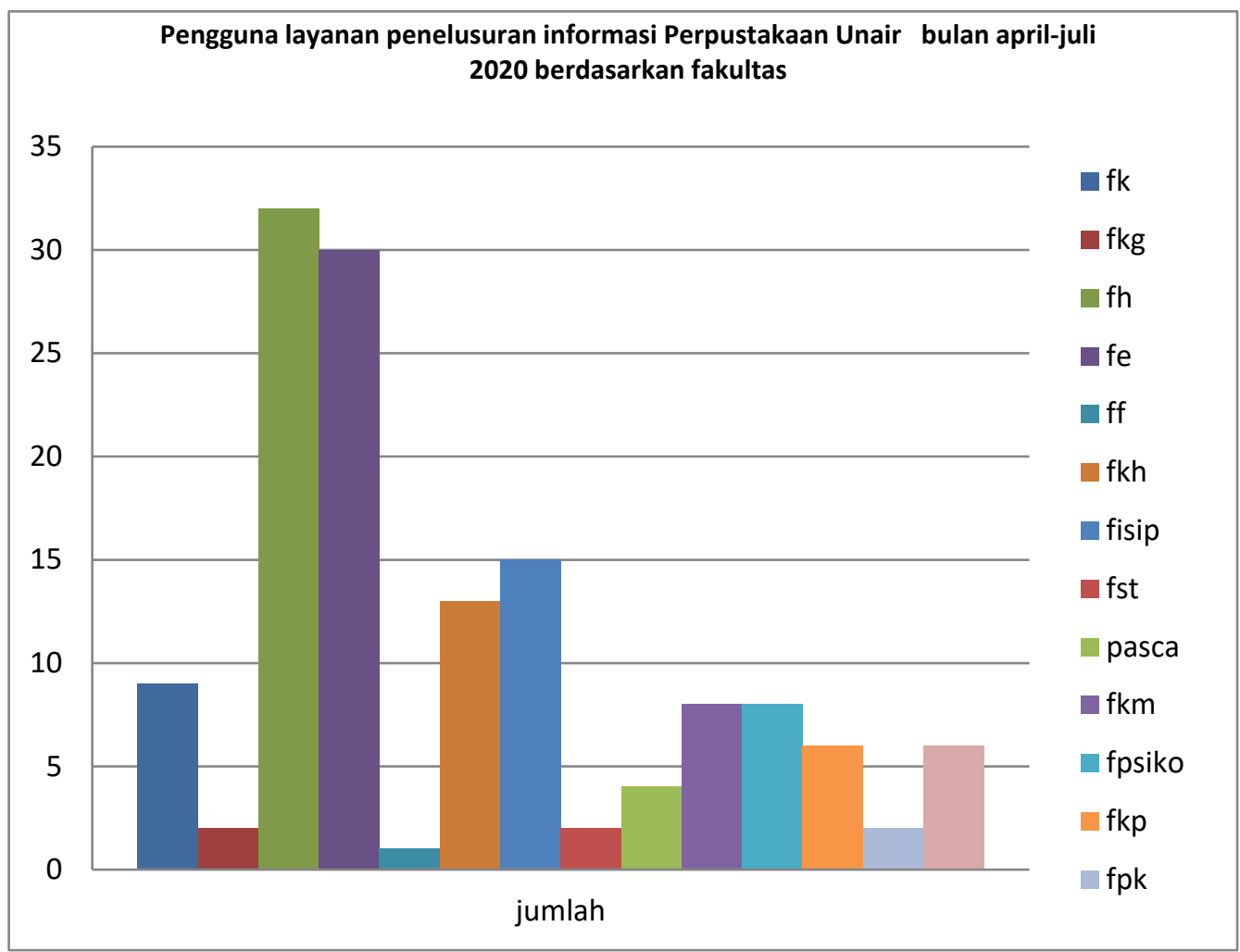

Gambar 4. Grafik Pengguna Layanan Penelusuran Informasi April-Juli 2020 berdasarkan Fakultas

Sumber: diolah dari data primer

Menilik lebih lanjut, berikut adalah grafik pengguna layanan penelusuran informasi berdasarkan fakultas pada bulan April-Juli 2020. Berdasarkan grafik diatas, dapat diketahui bahwa pengguna paling sedikit yang menggunakan layanan penelusuran informasi Perpustakaan UNAIR yaitu dari Fakultas Farmasi; 1 Fakultas Kedokteran Gigi;, Fakultas Sain Teknologi, , dan Fakultas Perikanan dan Kelautan dengan masing-masing 2 pengguna. Sedangkan pengguna paling banyak berasal dari Fakultas Hukum sebanyak 32 pengguna.

Berdasarkan data diatas, dapat diketahui kendala yang dihadapi oleh Perpustakaan UNAIR yaitu adanya intensitas penggunaan layanan penelusuran informasi yang cukup , Hal ini disebabkan mahasiswa menggunakan remotex untuk mengakses e resources yang dilanggan oleh Perpustakaan Unair

\section{Efektivitas Layanan Penelusuran Informasi Perpustakaan UNAIR}

Aktivitas penelusuran informasi pengguna dalam lingkungan perguruan tinggi perlu mendapat dukungan dari pustakawan sehingga sumber informasi yang disediakan perpustakaan dapat didayagunakan secara maksimal. Melihat evaluasi yang telah dipaparkan 
diatas, Perpustakaan UNAIR melakukan strategi agar penggunaan layanan penelusuran informasi dapat meningkat, diantaranya yaitu:

Pertama, memberikan bimbingan secara individual kepada pengguna dalam memanfaatkan sumber-sumber informasi yang telah disediakan. Banyak pemustaka yang kurang mengetahui bagaimana menggunakan sumber informasi elektronik atau digital yang disediakan maupun yang dilanggan perpustakaan. Ketidaktahuan ini akan berimbas pada penggunaan layanan penelusuran informasi perpustakaan UNAIR yang sedikit. Sehingga, diperlukan bimbingan kepada pengguna dalam pemanfaatan layanan penelusuran informasi. Salah satunya dengan melakukan bimbingan terkait cara penggunaan berbagai fitur yang ada dan strategi penelusuran informasi (Hasugian, 2006). Untuk hal ini perpustakaan melalui divisi latbang sudah menyediakan sarana agar mahasiswa mengikuti kegiatan ORM ( online research management )Strategi penelusuran yang bisa diedukasi kepada pengguna yaitu seperti: 1 . Menentukan bagaimana memulai penelusuran yaitu dengan menentukan kata kuncinya, 2. Menggunakan fitur search option untuk mempersempit penelusuran, 3. Pencarian bisa dilimitasi dengan membatasi sesuai dengan kategori yang ada tahun, fulltext, jenis sumber informasi, dan sebagainya, 4. Bagaimana menyimpan hasil pencarian yang didapatkan. Strategi lain yang bisa digunakan untuk melakukan penelusuran informasi yaitu dengan menggunakan BOLEAN LOGIC(Hasugian, 2006). Pustakawan melakukan bimbingan kepada pengguna terkait bagaimana BOLEAN LOGIC digunakan dan apa saja BOLEAN LOGIC. Dengan menggunakan hal ini, pencari informasi akan mendapatkan berbagai keuntungan, diantaranya: iinformasi yang ditemukan banyak dan luas, memperoleh informasi yang relevan, menghemat waktu pencarian, dan mempermudah penncarian.

Kedua, pustakawan mendayagunakan informasi dari sumber digital untuk menjawab kebutuhan pemustaka (Nelisa \& Ardoni, 2018). Hal ini dapat menarik minat pengguna untuk melakukan penelusuran dan menggunakan sumber informasi digital yang telah disediakan dan dilanggan perpustakaan.

Ketiga, pustakawan melakukan promosi terkait layanan penelusuran informasi (Nelisa \& Ardoni, 2018). Selain ketiga upaya diatas perpustakaan harus melakukan promosi sehingga dapat menarik pengguna dan meningkatkan penggunaan layanan penelusuran informasi. Saat ini, media sosial sudah marak digunakan untuk melakukan promosi perpustakaan dan dapat menjangkau lebih banyak pemustaka. Sehingga, layanan penelusuran informasi bisa dipromosikan pula dalam media sosial perpustakaan.

\section{PENUTUP \\ KESIMPULAN}

Pandemi COVID-19 yang mewabah di seluruh dunia mempengaruhi berbagai aspek dalam kehidupan masyarakat. Perpustakaan perguruan tinggi dan civitas akademik di dalam perguruan tinggi juga tak luput dari dampak pandemi ini. Seluruh kegiatan yang biasanya dapat dilakukan dengan interaksi secara langsung khususnya dalam mengakses informasi di perpustakaan, saat ini dibatasi oleh aturan dan kebijakan yang berlaku. Meski begitu, adanya teknologi informasi yang kian hari berkembang, pustakawan dapat merespons dengan cepat tantangan yang ada. Adanya teknologi informasi dapat dimanfaatkan pustakawan untuk menyediakan layanan yang berbasi teknologi informasi, salah satunya layanan penelusuran 
informasi secara online. Layanan penelusuran informasi di Perpustakaan UNAIR memanfaatkan OPAC, koleksi jurnal elektronik dan buku digital koleksi perpustakaan, serta bimbingan menelusur informasi digital seperti buku digital di berbagai website dan aplikasi yang bisa diakses secara gratis. Meski begitu, peningkatan layanan ini harus terus dilakukan agar penggunaan layanan ini bisa diakses oleh lebih banyak pengguna perpustakaan atau pemustaka.

\section{SARAN}

Pada penelitian selanjutnya diharapkan menggunakan metode kualitatif dengan subjek penelitian pustakawan di perguruan tinggi negeri dan swasta, sehingga mampu mendaptkan deskripsi hasul penelitian yang lebih luas, medalam dan komprehensif. Peneliti selanjutnya dapat mengambil tema mengenai kemampuan pustakawan dalam masa pandemic Covid-19 serta kemampuannya mengoperasikan teknologi Informasi

\section{DAFTAR PUSTAKA}

Ane Landøy Collaboration In Designing A Pedagogical Approach In Information Literacy// springer 2020

Hasugian, J. (2006). Penelusuran Informasi Ilmiah Secara Online : Perlakuan terhadap Seorang Pencari Informasi sebagai Real User Jonner Hasugian Departemen Studi Perpustakaan dan Informasi, 2(1), 1-13.

Ingvaldsen, S. (2017). Media And Information Literacy In Higher. United Kingdom.

Martoatmojo, K. (1993). Pelayanan Bahan Pustaka. Jakarta: Universitas Terbuka.

Nelisa, M., \& Ardoni. (2018). Penelusuran Informasi pada Pemustaka Universitas Negeri Padang. Journal of Library and Information Science, 2(1), 55-70. https://doi.org/http://dx.doi.org/10.18326/pustabiblia.v2i1.55-70

Purwono. (2008). Strategi Penelusuran Informasi Melalui Internet (pp. 1-13). Jakarta.

Reynaldi, \& Rahmah, E. (2014). Sarana Penelusuran Informasi di UPT Perpustakaan Proklamator Bung Hatta Bukittinggi, 33-40.

Yusuf, P. M., \& Subekti, P. (2010). Teori dan praktik penelusuran informasi information retrieval. Jakarta: Kencana. 